\title{
Commentary: Trials of off- versus on-pump bypass surgery: 105 and counting...
}

\author{
Mario Gaudino, MD, ${ }^{\mathrm{a}}$ Andre Lamy, $\mathrm{MD},{ }^{\mathrm{b}}$ and A. Laurie Shroyer, $\mathrm{PhD}^{\mathrm{c}}$
}

\footnotetext{
From the ${ }^{\mathrm{a}}$ Department of Cardiothoracic Surgery, Cornell Medicine, New York, NY; ${ }^{\mathrm{b}}$ Population Health Research Institute, McMaster University, Hamilton, Ontario, Canada; and ${ }^{\mathrm{c}}$ Research and Development Office, Northport Veterans Affair Medical Center, Northport, NY.

Disclosures: Authors have nothing to disclose with regard to commercial support.

Received for publication Sept 24, 2019; revisions received Sept 24, 2019; accepted for publication Sept 25, 2019; available ahead of print Oct 8, 2019.

Address for reprints: Mario Gaudino, MD, Department of Cardiothoracic Surgery, Weill Cornell Medicine, $525 \mathrm{E}$ 68th St, New York, NY 10065 (E-mail: mfg9004@med.cornell.edu).

J Thorac Cardiovasc Surg 2021;161:1283-4

$0022-5223 / \$ 36.00$

Copyright (c) 2019 by The American Association for Thoracic Surgery

https://doi.org/10.1016/j.jtcvs.2019.09.136
}

In this issue of the Journal, Szwed and colleagues ${ }^{1}$ report the result of a small, single-center randomized trial comparing off-pump surgery (OPCABG), anaortic OPCABG, and OPCABG $+\mathrm{CO}_{2}$ insufflation. The trial was powered to detect a $50 \%$ reduction in the incidence of early postoperative cognitive dysfunction (defined as reduction $\geq 20 \%$ in the score of 2 domains of the neuropsychological tests) between the anaortic and conventional OPCABG group. No power calculation was performed for the OPCABG $+\mathrm{CO}_{2}$ arm. A secondarynot powered-outcome was postoperative delirium assessed using the Confusion Assessment Method for the Intensive Care Unit. The results showed significantly lower rates for both neurologic endpoints in the anaortic $\mathrm{OPCABG}$ but not for the OPCABG $+\mathrm{CO}_{2}$ group.

The use of surrogate outcomes in clinical trials has the main advantage of reducing the sample size and providing hypothesis-generating data to be tested on a larger scale. However, to do so, surrogate outcomes must be intrinsically linked with relevant clinical outcomes, so that a variation in the former is highly suggestive of a possible variation in the latter. Herein lies the problem, as the clinical significance of the changes in neuropsychological test findings is far from clear.

After a period of enthusiasm in the 1990s, neuropsychological tests fell out of favor in the scientific community because of their limited clinical relevance. Although a $20 \%$ score reduction for at least 2 domains has been a historically used as the outcome in studies using neuropsychological tests, the clinical impact is unclear. It is also worth noting that in the trial of Szwed and colleagues, the incidence of stroke (as the preferred clinical outcome) in the OPCABG group was very high $(3.1 \%)$; this is even more concerning, as this patient population is young (mean age 66 years) and at low surgical risk (mean EuroScore 0.9). In the largest OPCABG trials, stroke incidence was consistently $\sim 1 \%$, even for high-risk populations such as septuagenarians included in the German Off-Pump Coronary Artery Bypass

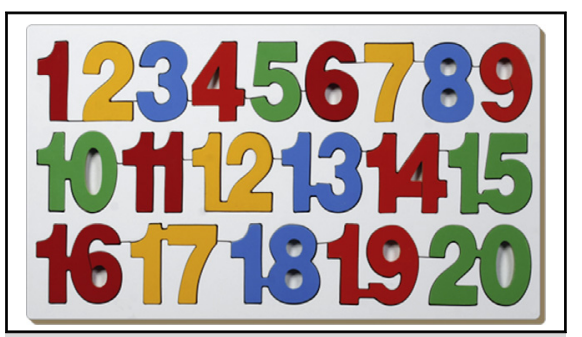

Off- versus on-pump coronary bypass: 105 trials and counting.

Central Message

The hypothesis that anaortic coronary bypass grafting reduces perioperative neurologic events should be formally tested by future randomized trials.

See Article page 1275.

Grafting in Elderly Patients (GOPCABE) trial..$^{2-4}$ Therefore, the differences reported by Szwed and colleagues may be potentially related to more stroke events occurring in the control group versus a positive clinical benefit documented for their experimental group.

Coronary bypass surgery is probably the most studied of all surgical procedures, and OPCABG has by far received the greatest level of scientific scrutiny. To date, at least 104 randomized trials have compared on- versus offpump coronary bypass surgery. ${ }^{5}$ More recently, anaortic OPCABG has been shown to reduce the risk of perioperative stroke in observational studies that, by definition, are open to treatment allocation bias and hidden confounders. ${ }^{6}$ The "anaortic hypothesis" has never been formally tested in a randomized trial. Although a mechanistic trial exploring the anaortic hypothesis would be a welcome addition to the literature, the data presented by Szwed and coauthors do not yet provide definitive information. Thus, the rationale remains for a much-needed trial to test this "anaortic hypothesis."

\section{References}

1. Szwed K, Pawliszak W, Szwed M, Tomaszewska M, Anisimowicz L, Borkowska A. Reducing delirium and cognitive dysfunction after off-pump coronary bypass: a randomized trial. J Thorac Cardiovasc Surg. 2021;161: 1275-82.e4.

2. Diegeler A, Börgermann J, Kappert U, Breuer M, Böning A, Ursulescu A, et al Off-pump versus on-pump coronary-artery bypass grafting in elderly patients. $N$ Engl J Med. 2013;368:1189-98. 
3. Shroyer AL, Hattler B, Wagner TH, Collins JF, Baltz JH, Quin JA, et al. Five-year outcomes after on-pump and off-pump coronary-artery bypass. $N$ Engl J Med. 2017;377:623-32.

4. Lamy A, Devereaux PJ, Prabhakaran D, Taggart DP, Hu S, Straka Z, et al. Five-year outcomes after off-pump or on-pump coronary-artery bypass grafting. N Engl J Med. 2016;375:2359-68.
5. Gaudino M, Benedetto U, Bakaeen F, Rahouma M, Tam DY, Abouarab A, et al. Off- versus on-pump coronary surgery and the effect of follow-up length and surgeons' experience: a meta-analysis. J Am Heart Assoc. 2018;7:e10034.

6. Zhao DF, Edelman JJ, Seco M, Bannon PG, Wilson MK, Byrom MJ, et al. Coronary artery bypass grafting with and without manipulation of the ascending aorta: a network meta-analysis. J Am Coll Cardiol. 2017;69:924-36. 